DOI: https://doi.org/10.30749/2594-8261.v5n3p34-58

\title{
O CONSELHO NACIONAL DOS DIREITOS DA MULHER E A ASSEMBLEIA NACIONAL CONSTITUINTE EM 1987 E 1988: A REPRESENTAÇÃO POLÍTICA QUE REVOLUCIONOU OS DIREITOS DAS MULHERES NO BRASIL
}

\section{THE NATIONAL COUNCIL OF WOMEN'S RIGHTS AND THE CONSTITUENT NATIONAL ASSEMBLY IN 1987 AND 1988: POLITICAL REPRESENTATION THAT REVOLUTIONIZED WOMEN'S RIGHTS IN BRAZIL}

Bibiana Terra ${ }^{1}$

Resumo: $O$ presente artigo tem como objetivo geral analisar a participação e representação política do Conselho Nacional dos Direitos da Mulher (CNDM) no último processo constituinte brasileiro, que ocorreu entre 1987 e 1988. O CNDM foi um órgão criado pelo governo federal em 1985 com a intenção de promover e estimular a participação das mulheres da sociedade civil junto ao Estado. Diante disso, essa pesquisa procurou investigar como o contexto histórico-político da constituinte revolucionou a maneira de atuar do movimento feminista, representado por esse Conselho, na conquista dos direitos das mulheres na Constituição Federal. Através dele foi elaborado um importante documento, denominado de Carta das Mulheres Brasileiras aos Constituintes, que aborda as principais reivindicações femininas para o novo texto constitucional que estava por vir. Para essa análise, que se insere no campo teórico, foi adotada a metodologia da pesquisa bibliográfica, desenvolvendo estudo exploratório com base em material já elaborado, e o seu referencial teórico foi construído principalmente a partir das obras de teóricas feministas brasileiras. Diante disso, traz como resultados que a atuação do CNDM pode ser considerada como um ato revolucionário na história dos direitos das mulheres brasileiras, sendo que essa foi uma revolução para além da constituinte, pois além de lograr êxito na previsão constitucional desses direitos, também abriu espaço para uma atuação institucional do feminismo no país.

Palavras-chave: Conselho Nacional dos Direitos da Mulher. CNDM. Feminismo. Direito das mulheres. Constituição Federal de 1988.

\footnotetext{
${ }^{1}$ Mestra em Direito, com ênfase em Constitucionalismo e Democracia, na Linha de Pesquisa Relações Sociais e Democracia, pela Faculdade de Direito do Sul de Minas - FDSM (2021). Especialista em Direito Internacional pela Escola Brasileira de Direito - EBRADI (2021). Especialista em Direito Constitucional pela Universidade Anhanguera-Uniderp (2020). Graduada em Direito pela Pontifícia Universidade Católica de Minas Gerais - PUC Minas (2018).
} 
Abstract: This article aims to analyze the participation and political representation of the National Council for Women's Rights (CNDM) in the last Brazilian constituent process, which took place between 1987 and 1988. The CNDM was a body created by the federal government in 1985 with the intention to promote and encourage the participation of women from civil society in the State. Therefore, this research sought to understand how the historical-political context of the constituent revolutionized the way the feminist movement, represented by this Council, acts in the conquest of women's rights in the Federal Constitution. Through it, an important document was prepared, called the Letter of Brazilian Women to the Constituents, which addresses the main female demands for the new constitutional text that was to come. For this analysis, which is part of the theoretical field, the methodology of bibliographical research was adopted, developing an exploratory study based on material already prepared, and its theoretical framework was built mainly from the works of Brazilian feminist theorists. Therefore, it brings as results that the performance of the CNDM can be considered a revolutionary act in the history of Brazilian women's rights, and this was a revolution beyond the constituent one, as in addition to achieving success in the constitutional provision of these rights, it also opened space for an institutional role of feminism in the country.

Keywords: National Council for Women's Rights. CNDM. Feminism. Women's rights. Federal Constitution of 1988. 


\section{INTRODUÇÃO}

Os movimentos feministas no contexto brasileiro, na década anterior à constituinte de 1987 e 1988, já se impunham como importantes agentes no cenário político do país. Esses movimentos sociais, ainda dando os seus primeiros passos e tentando se organizar, adquiriram ao longo dos anos 1970 e início de 1980 uma grande força política. Naquele período eles lutavam contra o regime autoritário e, assim, buscavam a restauração da democracia. No entanto, essa busca pela redemocratização não dizia respeito apenas às instituições políticas, mas também às relações entre homens e mulheres nas esferas sociais e jurídicas.

Diante disso, em 1985, em um cenário de mobilizações pelas Diretas-Já ${ }^{2}$ e pela redemocratização do Brasil, as mulheres e as feministas brasileiras passaram a debater a respeito da necessidade de criação de um órgão de âmbito federal que fosse capaz de elaborar e desenvolver nacionalmente leis e políticas públicas voltadas especificamente para as mulheres. Desse modo, esse órgão teria como objetivo central elaborar uma agenda política que visasse a melhorar a condição feminina, sendo que para tanto esse teria o trabalho de propor a elaboração de novas legislações, programas e aconselhamento para a presidência e para os ministérios no desenvolvimento de projetos específicos para as mulheres.

Sendo assim, em agosto daquele ano, o governo federal, através do então presidente da República, José Sarney, criou o Conselho Nacional dos Direitos da Mulher - conhecido nacionalmente pela sua sigla CNDM, que se tornaria um importante instrumento de mobilização das mulheres brasileiras por suas reivindicações. Esse órgão foi de fundamental importância para as brasileiras, sendo que contribuiu para que as feministas passassem a ocupar espaços institucionais e impulsionou as discussões que antecederam a Assembleia Constituinte de 1987 e 1988. Além disso, esse Conselho, durante todos os trabalhos desempenhados pela constituinte, desenvolveria contribuições significativas para as mulheres e as

\footnotetext{
2 "Diretas-já" foram as campanhas iniciadas no final de 1983 com o objetivo de pressionar governos e políticos a proporem eleições diretas para Presidente da República (RODRIGUES, 1990, p. 13).
} 
feministas, contribuindo para uma maior representação (e participação) delas na política e nos espaços públicos.

Diante disso, partindo da compreensão de que os trabalhos desempenhados pelo CNDM durante o período da constituinte foram fundamentais para a ampliação da cidadania feminina, o presente artigo tem como objetivo central analisar a participação e representação política do Conselho Nacional dos Direitos da Mulher durante a última Assembleia Nacional Constituinte, que ocorreu entre 1987 e 1988 . $^{3}$ Sendo assim, tenta resgatar a história desse importante órgão que atuou na articulação entre os mecanismos de decisão política e as mulheres brasileiras, e que mudou a forma de representação política das mesmas, mas que no entanto é um órgão que foi esquecido por grande parcela do direito.

Para essa análise, que se insere no campo teórico, nos estreitos limites deste trabalho, serão desenvolvidos dois objetivos específicos. Em um primeiro momento será feito um resgate histórico do movimento feminista no Brasil, em que serão abordadas as suas principais reivindicações ao longo do tempo, até o período da abertura de uma nova Assembleia Constituinte. Já no segundo momento, será trabalhado o período de elaboração do novo texto constitucional, com ênfase na criação e atuação do Conselho Nacional dos Direitos da Mulher e os seus objetivos de ampliar a cidadania feminina e garantir os seus direitos na nova Constituição Federal que passava a ser redigida.

Essa pesquisa se justifica pois, apesar da importante atuação desse Conselho e embora a historiografia constitucional brasileira, assim como a literatura jurídica e política nacional, tenha registrado e analisado importantes aspectos da Assembleia Nacional Constituinte de 1987 e 1988, deixou de considerar a atuação do CNDM. A participação e contribuição do Conselho Nacional dos Direitos da Mulher durante os trabalhos da Assembleia Constituinte de 1987/1988, mesmo com

\footnotetext{
${ }^{3}$ Os limites cronológicos desta pesquisa têm como recorte temporal a atuação do CNDM a partir da data da criação desse órgão, em 1985, até 1988, momento em que há a promulgação da Constituição Federal. O período delimitado se justifica pois o artigo tem como objeto de estudo a atuação e contribuição deste Conselho durante os trabalhos desempenhados pela Assembleia Nacional Constituinte.
} 
- lapso temporal de pouco mais de 30 anos, ainda é um tema escassamente explorado nos trabalhos jurídicos brasileiros e, diante disso, essa pesquisa pretende contribuir para a superação dessa lacuna e para auxiliar na compreensão do avanço dos direitos das mulheres no Brasil, tomando a atuação do CNDM como revolucionária, pois este mudou a forma de desempenho dos movimentos feministas e também a representação política das mulheres brasileiras.

Para tanto, é utilizada como metodologia a realização de pesquisa de natureza exploratória, por meio de adoção do método bibliográfico, vez que este diz respeito à parte dedicada à contextualização teórica do problema e a sua relação com o que já tem sido investigado a seu respeito. Utilizando como base materiais elaborados, constituídos principalmente por livros e artigos científicos que versam quanto à temática dos direitos das mulheres, constituinte e de gênero. Nesse sentido, o seu referencial teórico será construído majoritariamente a partir de textos e obras de teóricas feministas brasileiras.

\section{AS PRIMEIRAS MOVIMENTAÇÕES FEMINISTAS NO BRASIL: DA CONQUISTA DOS DIREITOS POLÍTICOS DAS MULHERES ATÉ O PERÍODO DA REDEMOCRATIZAÇÃO DO PAÍS}

Os feminismos se desenvolveram ao longo da história como movimentos políticos, sociais e também filosóficos, sendo que uma das suas principais características é a busca pela igualdade entre homens e mulheres e, consequentemente, por direitos iguais para todos. Esses podem ser compreendidos como movimentos que reivindicam pela participação igualitária das mulheres na sociedade, pela desconstrução da figura da mulher como subalterna do homem e, assim, de maneira ampla, são movimentos que buscam a superação das hierarquias de gênero (TELES, 2017).

Partindo dessa definição, é possível compreender que os movimentos feministas são fundamentais para a construção de identidades políticas femininas, visto que é uma reunião estruturada de ideias que guia ações políticas. Nesse 
sentido, os feminismos partem da noção de que as mulheres são discriminadas e não gozam dos mesmos direitos e condições de igualdade que os homens. Além disso, compreendem que essas diferenças são resultado da desigualdade estrutural das mulheres em meio a sociedade e do reconhecimento de que são necessárias soluções coletivas para que haja mudanças estruturais (AVELAR, 2001).

No Brasil, as primeiras movimentações feministas se deram ainda no século XX, através das reivindicações de mulheres como Nísia Floresta. Naquele momento, no país, havia um número reduzido de periódicos que eram editados por mulheres e que apresentavam reflexões críticas sobre os papéis desempenhados por elas na sociedade, sendo que esses foram importantes para apresentarem as demandas das mulheres e as lutas por seus direitos. Elas afirmavam acerca da necessidade de receberem instrução para a sua emancipação social (CHAKIAN, 2020).

As reivindicações das mulheres por direitos iguais de cidadania - direito à educação, propriedades e posses de bens, divórcio, entre outros, marcaram o início das suas movimentações, sendo que a sua pauta principal nesses períodos dizia respeito ao direito ao sufrágio feminino, ou seja, o direito de participação política. Assim, no começo do século XX, as mulheres buscavam a igualdade política e jurídica entre os sexos, sendo que o voto feminino era a principal conquista a ser alcançada por elas, que até então viviam excluídas dessa esfera, relegadas ao âmbito doméstico (PINTO, 2003).

Os direitos políticos - direito de votar e ser votada - foi uma das mais marcantes e relevantes batalhas das mulheres, no mundo todo, na busca pela sua igualdade de gênero. No contexto brasileiro, a ideologia patriarcal e machista era detentora das relações de poder na sociedade, sendo que essa reforçava, por meio das legislações (código civil, código penal e Constituição, dentre outras leis), os papéis sociais de esposa e mãe. Sendo assim, a base da discussão acerca dos direitos políticos das mulheres brasileiras foi a família, um local patriarcal e de subalternidade feminina (LUZ; SIMÕES, 2016). 
Desse modo, fica evidente que a ideologia patriarcal era detentora das relações de poder na sociedade, tendo reforçado os papéis sociais de esposa e mãe, inclusive por meio das legislações - ou seja, essas discriminações tinham estatuto formal (BIROLI, 2018). Assim, a própria lei excluía as mulheres, excluindo-as dos espaços públicos. No Brasil, as mulheres, desde o Império e até mesmo após o advento do Código Civil de 1916, eram excluídas da política, sendo que quando elas participavam, eram representadas por seus pais ou maridos, mas nunca por elas mesmas (LUZ; SIMÕES, 2016).

Nessa época, com o sistema patriarcal ainda mais dominante do que é hoje, este pode ser considerado o principal responsável por manter a imagem das mulheres meramente como esposas e mães, excluídas da vida pública e dos espaços de tomadas de decisões. Sendo assim, o voto feminino foi durante muito tempo negado e postergado devido a esses motivos, pois os homens alegavam que elas deveriam cumprir com os papéis determinados para o seu gênero, pois a vida política cabia a eles, sendo que elas deveriam ser mantidas no espaço doméstico. Todavia, diante de um cenário de constante exclusão e opressão das mulheres, passaram a surgir as primeiras manifestações femininas que contestavam esse lugar tradicionalmente atribuído à mulher brasileira (LUZ; SIMÕES, 2016).

O Partido Republicano Feminino, PRF, criado por Leolinda Daltro, foi a primeira organização brasileira a articular esforços para alcançar o sufrágio feminino no Brasil. Embora essa organização não tenha alcançado êxito (porque na época as mulheres não conquistaram o direito ao voto), foi bastante importante naquela época, tendo chamado a atenção acerca dos direitos políticos das mulheres brasileiras (KARAWEJCZYK, 2019). Mesmo com o seu encerramento em 1910, as reivindicações não pararam, pelo contrário, passaram a ganhar cada vez mais espaço e força, sendo que a volta de Bertha Lutz ao país, depois de ter passado um tempo estudando e trabalhando na Europa, daria início a novas organizações, inaugurando o momento mais expressivo das sufragistas brasileiras (AVELAR, 2001). 
Nesse contexto, no Brasil, no ano de 1919 é fundada, por Bertha Lutz, a LEIM, Liga pela Emancipação Intelectual da Mulher, que posteriormente, em 1922, ganharia um novo nome, sendo nacionalmente conhecida como Federação Brasileira pelo Progresso Feminino - FBPF. Essa Federação foi fundamental para as mulheres brasileiras, sendo que foi através dela que as reivindicações pelo sufrágio feminino no Brasil continuaram crescendo e, finalmente, em 1932 elas alcançaram êxito, depois de décadas de reivindicações, pois naquele ano, durante o governo provisório de Getúlio Vargas, foi editado o Decreto n 21.076 que instituiu o primeiro Código Eleitoral brasileiro e trouxe em seu artigo $2^{\circ}$ o direito ao voto feminino, pois estabeleceu que seria eleitor o cidadão maior de 21 anos, sem distinção de sexo, alistado na forma do código (ALVES, 2019).

Essa foi uma conquista histórica para as mulheres brasileiras, sendo que consagrou décadas de mobilizações políticas pelas feministas em favor do sufrágio feminino no Brasil. Após essa conquista, as reivindicações desse movimento só ganhariam força novamente nos anos 1960, sendo que a partir de então os debates a respeito dos direitos das mulheres voltaram à tona através de reivindicações pela valorização do trabalho da mulher, pelos seus direitos sexuais e reprodutivos. Assim, surge então um novo feminismo brasileiro, que passou a apresentar reivindicações para além dos direitos políticos e educacionais, pois as questões ligadas à sexualidade, ao prazer feminino, ao corpo, violência doméstica, discriminações de gênero e direitos reprodutivos ganharam cena dentro das discussões feministas (PEDRO, 2018).

Nesse contexto, é importante destacar que o Brasil passava por um período de ditadura militar, desde 1964, ano de sua instauração, e que perduraria até pelo menos a primeira metade da década de 1980. A repressão no país era muito forte, tendo acarretado radicais mudanças na política. Apesar desse contexto repressivo, as mulheres e os movimentos feministas, em certas medidas, conseguiram reivindicar por seus direitos, sendo que elas sofreram diversas influências das feministas do exterior, que se organizavam principalmente na Europa e Estados 
Unidos (TELES, 2017). Essas reivindicações não diziam respeito apenas a questões de gênero, mas também pela volta do regime democrático no Brasil.

\begin{abstract}
De 1975, marco do movimento feminista no mundo e no Brasil, até 1979, quando o país dá os primeiros passos firmes em direção à democratização, com a anistia e a reforma partidária que terminou com o bipartidarismo, o movimento feminista no Brasil esteve associado muito de perto à luta pelo fim do regime militar. $O$ encontro do feminismo à moda do Primeiro Mundo com a realidade brasileira daquela década promoveu situações tão complicadas quanto criativas: as mulheres de classe média, intelectualizadas, que estiveram nos Estados Unidos ou na Europa como exiladas, estudantes ou simples viajantes em busca de novas experiências, voltavam para o Brasil trazendo uma nova forma de pensar sua condição de mulher, em que o antigo papel de mãe, companheira, esposa não mais servia. (...) Mas o Brasil que encontravam era um país dominado por uma ditadura sangrenta, na qual todas as frestas de expressão que sobrara deviam ser ocupadas pela luta pró-democratização, pelo fim da censura, pela anistia aos presos políticos e exilados (PINTO, 2003, p. 65).
\end{abstract}

Diante disso, pode-se compreender que nesse momento, no Brasil, a situação política influenciou os movimentos feministas, pois o país vivenciava um regime ditatorial que perduraria por 21 anos, de 1964 até 1985, e que seria marcado pelo autoritarismo político e pela violação dos direitos humanos (PINTO, 2003). Desse modo, é importante compreender que embora as brasileiras tenham sido influenciadas pelo feminismo internacional, o contexto aqui era bastante diferente, sendo que para além das suas reivindicações por igualdade de gênero, o feminismo brasileiro nesse período foi significativamente marcado pela contestação à ordem política instituída no país. As feministas desenvolveram um papel fundamental na resistência à ditadura militar, conjugando a luta dos direitos das mulheres com as reivindicações pela volta da democracia (TELES, 2017).

Nessas circunstâncias, já com o período de transição democrática no início da década de 1980, as brasileiras passaram a questionar acerca da necessidade de órgãos institucionais que as auxiliassem em seus reivindicações e, assim, elas voltaram sua atenção para o Estado e o seu aparato institucional como o lugar que elas precisavam passar a ocupar. Desse modo, os movimentos feministas passaram 
a reunir esforços para a criação de órgãos e mecanismos institucionais que tivessem como objetivo a garantia dos direitos das mulheres (BIROLI, 2018).

No Brasil, os movimentos feministas tiveram grande protagonismo em momentos-chave de nossa história contemporânea, como no processo de transição da ditadura de 1964 para um regime democrático, nos anos 1980, em que se destacaram as disputas para a construção da nova carta constitucional de 1988. Desde então, sua atuação sistemática tem imprimido perspectivas de gênero a instituições e políticas, o que foi interpretado como um processo de despatriarcalização do Estado. Há, assim, boas razões para se pensar o atrelamento da participação nos espaços formais à atuação de movimentos e organizações feministas e de mulheres (BIROLI, 2018, p. 175).

Inicialmente a construção de órgãos políticos voltados para a população feminina passaram a surgir em nível estadual, sendo que foram criados conselhos em estados tais como São Paulo, Rio de Janeiro, Rio Grande do Sul, dentre outros. Esses conselhos colocaram em debate a necessidade da participação das mulheres na restauração da democracia, tendo sido importantes para a ampliação das reivindicações pelos seus direitos e dos movimentos feministas no país (PITANGUY 2019). Assim, as feministas passaram a discutir sobre a necessidade da "criação de um órgão governamental de nível federal para influenciar na proposição de um marco normativo livre de discriminações e efetivar, no âmbito do executivo, políticas públicas voltadas para a condição feminina" (PITANGUY, 2019, p. 85).

Diante disso, durante as movimentações pelas eleições presidenciais naquele período, um grupo de mulheres, composto dentre elas por Jacqueline Pitanguy, Ruth Escobar, Tônia Carrero, entre outras, se engajou na proposição de um órgão federal que garantisse os direitos das mulheres e o avanço de suas pautas no Brasil. Essas mulheres se reuniram e foram se encontrar com Tancredo Neves, que seria candidato à presidência da República naquela época, para demandar o seu compromisso de que, caso o mesmo fosse eleito, ele tomasse as medidas necessárias para que fosse criado um ministério, um órgão, destinado a políticas públicas específicas para as mulheres (PIMENTA, 2010). 
Desse modo, os anos 1980 representaram o período de abertura democrática na história do Brasil, sendo que as suas transformações permearam o processo de redemocratização da sociedade brasileira e estiveram centradas na garantia dos direitos sociais e individuais e no abandono das práticas ditatoriais. $\mathrm{O}$ marco definitivo desse processo, além das eleições diretas para a presidência da República que colocaram fim ao regime militar, foram os trabalhos da Assembleia Nacional Constituinte de 1987/1988, que tinham o objetivo de elaborar uma nova Constituição Federal (PINTO, 2003).

\section{O CONSELHO NACIONAL DOS DIREITOS DA MULHER (CNDM) E O PROCESSO CONSTITUINTE DE 1987 E 1988}

$\mathrm{Na}$ década de 1980, com os esforços da sociedade pela volta da democracia, os movimentos feministas, no contexto brasileiro, deram início a uma fase de efervescência nas suas reivindicações pelos direitos das mulheres, fortalecendo e ampliando suas lutas (PINTO, 2010). Além disso, no Brasil, havia uma pauta que estava em evidência naquele momento, qual seja, a possibilidade da criação de uma nova Constituição Federal. Nessa conjuntura, uma parte do grupo das feministas tinha a compreensão de que elas não podiam perder a oportunidade de participar da constituinte e, desse modo, elas passaram a se articular para que fosse criado um órgão de âmbito federal que atuasse como um ministério e que desenvolvesse políticas públicas focadas exclusivamente para a população feminina, para garantir os seus direitos e ouvir as suas demandas (PITANGUY, 2018).

Diante disso, durante as mobilizações das campanhas pelas Diretas-Já, que haviam se iniciado desde 1983, e da instituição do Movimento de Mulheres pelas Diretas-Já, foi criado, no ano de 1985, o órgão que ficou denominado de Conselho Nacional dos Direitos da Mulher (CNDM). Esse tratava-se de um Conselho de âmbito federal e nasceu da iniciativa de 40 mulheres do PMDB (Partido do Movimento Democrático Brasileiro), que procuraram Tancredo Neves, quando esse 
ainda era candidato à presidência do Brasil, para obterem dele a garantia da instauração de um órgão estatal para cuidar dos direitos das mulheres. Com a sua morte, o vice-presidente José Sarney assumiu a presidência e manteve a promessa, tendo então criado o CNDM (PINTO, 2003).

Sendo assim, em 1985 o governo federal, através de Sarney, criou esse Conselho Nacional dos Direitos da Mulher, que se tornaria, em determinado momento, um importante instrumento de mobilização das mulheres e dos movimentos feministas por suas reivindicações. Esse órgão traria inúmeros direitos para as brasileiras, ampliando a cidadania feminina. Nesse sentido, ele contribuiu de forma significativa para que as feministas passassem a ocupar espaços institucionais e foi fundamental para as discussões que antecederam a Assembleia Nacional Constituinte em 1987 e 1988 (PITANGUY, 2019).

Assim, já de início, desde o momento de sua criação, é possível compreender que esse órgão revolucionou e, posteriormente, durante o processo constituinte, revolucionaria ainda mais, a participação e representação das mulheres brasileiras, dando abertura para que elas dialogassem e apresentassem suas pautas e demandas em espaços estatais. A sua criação foi muito importante para as mulheres e as feministas do país, pois colocou, nacionalmente, as discussões acerca dos direitos das mulheres em destaque, pois este tratava-se de um órgão de nível federal e que ficou amplamente conhecido.

O CNDM se organizou através de comissões por áreas de trabalho, envolvendo temas como violência de gênero, saúde, educação, cultura, mulher negra, mulher rural, entre outras. A sua criação, em agosto de 1985, se deu através da Lei 7.353 (BRASIL, 1985), que o definia como sendo um órgão federal com autonomia administrativa e orçamento próprio e que respondia diretamente ao Presidente da República, a quem cabia a nomeação de sua presidenta. A sua formação atendeu à demanda dos movimentos de mulheres e feministas que consideravam importante, para a reconstrução das instituições políticas democráticas e para a sua participação posterior na constituinte, que fosse proposta 
uma agenda de igualdade de direitos entre homens e mulheres e que esta fosse compatível de ser implementada por um órgão federal dotado de autonomia (PITANGUY, 2019). Diante disso, elas lograram êxito, sendo que o CNDM foi aprovado e criado em agosto de 1985.

A criação desse espaço institucional pode ser considerada como uma grande vitória por parte dos movimentos feministas e de mulheres preocupadas com seus direitos, sendo um marco muito importante para a ampliação das suas participações na política brasileira.

\begin{abstract}
Vinculado ao Ministério da Justiça, o CNDM respondia, no entanto, à Presidência da República. Tinha como finalidade promover, em âmbito nacional, políticas para a eliminação da discriminação contra a mulher, "assegurando-lhe condições de liberdade e de igualdade de direitos". Entre suas competências estavam a formulação de políticas para a "eliminação das discriminações que atingem a mulher", a assessoria ao poder Executivo e a proposição de medidas "nas questões que atingem a mulher", além da sugestão de projetos de lei à Presidência (...) (Lei 7.353, de 1985), expondo linguagens e preocupações presentes nos feminismos brasileiros naquele momento (BIROLI, 2018, p. 181).
\end{abstract}

O CNDM era composto por diferentes mulheres que integravam os movimentos feministas, sendo que podem ser citadas mulheres de grande renome dentro desses movimentos, tais como Lélia Gonzalez, Rose Marie Muraro, Jacqueline Pitanguy e a deputada estadual Ruth Escobar - a primeira mulher a presidi-lo, no momento de sua criação em 1985. Posteriormente a socióloga Jacqueline Pitanguy seria a sua presidenta, tendo atuado durante o período da Assembleia Nacional Constituinte em 1987 e 1988 (BIROLI, 2018).

Desde o momento em que este órgão foi criado, um dos principais cuidados que o Conselho Nacional teve foi o de planejar um programa que estivesse voltado para o novo processo constituinte que em breve seria instaurado. Para tanto, o CNDM lançou, em 1985, a campanha nacional "Mulher e Constituinte", que era amplamente divulgada através dos slogans "Constituinte para valer tem que ter palavra de mulher" e "Constituinte para valer tem que ter Direitos da Mulher". Esses dois slogans resumiam bem quais os objetivos das feministas e das mulheres 
brasileiras para aquele momento (LUZ; TERRA, 2021). Inspiradas por essas mensagens, elas passariam os meses antecedentes à constituinte se reunindo, estudando e debatendo suas principais reivindicações para o novo texto constitucional que passaria a ser redigido (PIMENTEL, 1987).

\begin{abstract}
A ação que culmina nas campanhas "Constituinte para valer tem que ter palavra de mulher" e "Constituinte para valer tem que ter direitos da mulher", capitaneadas pelo CNDM, expõe um modo de articulação de diferentes dimensões da atuação política feminista, diante de constrangimentos advindos do caráter masculino do Judiciário, dos partidos e do funcionamento do campo político (BIROLI, 2018, p. 182).
\end{abstract}

Desde que essas campanhas passaram a ser lançadas, as integrantes do CNDM se organizaram e começaram a viajar para diversos estados do Brasil com o objetivo de ouvir diferentes mulheres brasileiras e registrar quais eram as suas principais demandas para a constituinte. Nesse sentido, através dessas ações, elas ampliaram os canais de comunicação entre os movimentos sociais e os mecanismos de decisão política, pois compreendiam que dessa maneira elas conseguiriam uma real aproximação entre os movimentos feministas e as diferentes mulheres da sociedade civil. Assim, com essa comunicação mais facilitada entre elas, poderia haver uma compreensão mais ampla de quais eram as suas principais reivindicações para aquele momento (PITANGUY, 2019).

Diante disso, pode-se compreender que as campanhas nacionais "Mulher e Constituinte", para demandar os direitos das mulheres na nova Constituição Federal, tiveram seu início através da organização de eventos em diferentes cidades do país, pois havia um objetivo de que fossem alcançadas o maior número de mulheres possível, bem como de que diferentes demandas fossem ouvidas, pois diferentes mulheres tinham diferentes reivindicações. O CNDM se articulou com os movimentos de mulheres, com outros grupos de feministas e com entidades locais da sociedade civil, como Conselhos de âmbito estadual e municipal, e com Assembleias Legislativas. Assim, fica demonstrada a sua real preocupação em 
entender quais eram as demandas das mulheres para a constituinte (LUZ; TERRA, 2021).

Simultaneamente a essas reivindicações acerca dos direitos que elas queriam que fossem previstos no novo texto constitucional, o CNDM também demandava uma maior presença de mulheres na Assembleia Nacional Constituinte. As integrantes do Conselho compreendiam que, para que elas pudessem alcançar uma verdadeira democracia, essa deveria necessariamente contemplar os direitos das mulheres e a condição feminina, sendo que, para tanto, era preciso reconhecer a participação delas na sociedade brasileira, inclusive a sua participação política, ainda tão minoritária no contexto brasileiro (PINTO, 2003).

Elas tinham o entendimento de que não poderiam mais ficar relegadas à vida privada como sua única perspectiva de atuação na sociedade, excluídas da política, dos espaços de poder e de tomadas de decisões. A partir desse momento elas fariam parte dos espaços institucionais, o que acabou gerando uma consciência que permitiu que as mulheres brasileiras e as integrantes dos movimentos feministas percebessem sua força diante do cenário político que finalmente passava a se abrir para o debate depois de longos anos de repressão e autoritarismo político. Assim, elas enxergaram na constituinte uma real possibilidade de participarem da política.

Naquele momento houve uma grande resposta positiva por parte da sociedade brasileira ao CNDM, e importantes passos foram ali tomados com a participação ativa da sociedade. Diante dessa repercussão, esse Conselho redigiu o documento denominado de "Carta das Mulheres Brasileiras aos Constituintes", na qual foram apresentadas as propostas das mulheres e das feministas para a criação de uma ordenação normativa que evidenciasse a igualdade entre todas as pessoas, independentemente do seu gênero, sendo que era dever do Estado a sua garantia e aplicabilidade (PITANGUY, 2019). Esse documento foi entregue pela própria Jacqueline Pitanguy, que era a atual presidenta do Conselho, ao presidente da Assembleia Constituinte, Ulysses Guimarães, na abertura do novo processo 
constituinte em 1987, para que o mesmo tivesse conhecimento de quais eram as demandas das mulheres naquele momento (TERRA, 2021).

Sendo assim, a Carta das Mulheres à Constituinte foi um documento promovido pelo CNDM, mas de autoria de diversas mulheres da sociedade civil brasileira e dos movimentos feministas de diferentes regiões do país, sendo que pode ser considerado como um dos documentos mais importantes elaborados pelos movimentos feministas do Brasil (PINTO, 2003). A carta foi dividida em vários capítulos, sendo que entre eles foram abordadas questões referentes à família, trabalho, saúde, educação e cultura, violência e questões nacionais e internacionais, contemplando tanto questões gerais como demandas específicas de direitos das mulheres (PITANGUY, 2019). Assim, essa pode ser considerada como um documento bastante amplo.

Sendo assim, esse documento contemplava, em linhas gerais, as principais demandas das mulheres brasileiras, que já vinham sendo objeto de atuação de grupos envolvidos com os movimentos feministas. Conforme entendimento de Céli Regina Jardim Pinto, essa carta pode ser considerada como um dos documentos mais importantes elaborados pelo feminismo brasileiro contemporâneo (PINTO, 2003). A autora afirma que:

A "Carta das Mulheres", promovida pelo CNDM, mas de autoria de um conjunto muito amplo de mulheres chamadas a Brasília, foi o documento mais completo e abrangente produzido na época, e possivelmente um dos mais importantes elaborados pelo feminismo brasileiro contemporâneo. Está dividida em duas partes, a primeira propõe uma agenda que ultrapassa em muito os limites dos interesses corporativos das mulheres. Isso era especialmente importante por se tratar de uma intervenção a partir de um grupo que representava interesses de um movimento social tão específico. O documento defendia a justiça social, a criação do Sistema Único de Saúde, o ensino público e gratuito em todos os níveis, autonomia sindical, reforma agrária, reforma tributária, negociação da dívida externa, entre outras propostas. Na segunda parte, o documento detalhava as demandas em relação aos direitos da mulher no que se referia a trabalho, saúde, direitos de propriedade, sociedade conjugal, entre outros (PINTO, 2003, p. 75). 
Desse modo, dividida em duas partes, entre os princípios gerais e as suas reivindicações específicas, a Carta das Mulheres Brasileiras aos Constituintes contemplava as principais reivindicações das mulheres e das feministas que não poderiam ser deixadas de fora pela redação do novo texto constitucional. O CNDM entendia que, para que houvesse um efetivo desempenho e aplicação do Princípio da Igualdade, era necessário que a Constituição Federal estabelecesse preceitos legais que pudessem eliminar todas as formas de discriminação, inclusive aquelas em razão de sexo (PITANGUY, [2017]). Assim, elas buscavam garantir que houvesse um tratamento isonômico entre todas as pessoas.

O CNDM se organizou para trabalhar conjuntamente com os constituintes, com a bancada feminina e com outros representantes de órgãos e da sociedade civil que estariam presentes na constituinte para defender os direitos das mulheres. Sendo assim, as suas articulações foram fundamentais durante os trabalhos de preparação e, depois, durante o próprio período que foram realizados os trabalhos da Assembleia Nacional Constituinte em 1987 e 1988. A presença das mulheres nesse período se deu de diversas formas. Fizeram parte dele grupos de mulheres não necessariamente vinculados ao movimento feminista, as próprias feministas, as deputadas eleitas que formaram uma bancada feminina e o Conselho Nacional dos Direitos da Mulher (TERRA, 2021).

O então Presidente da República, José Sarney, no dia 28 de junho de 1985, encaminhou uma PEC (projeto de emenda constitucional) ao Congresso Nacional, com a proposta de convocação de uma Assembleia Nacional Constituinte. Esta proposta foi admitida, sendo que dela resultou a Emenda Constitucional n. ${ }^{\circ} 26$, de 27 de novembro de 1985. Assim, os parlamentares eleitos no pleito de 15 de novembro de 1986 - 487 Deputados Federais e 49 Senadores - e mais 23 dos 25 Senadores eleitos em 1982, num total de 559, deram início aos trabalhos do processo constituinte em $1^{\circ}$ de fevereiro de 1987, data da instalação da Assembleia Nacional Constituinte (PILATTI, 2019). 
Esse foi um período que durou 20 meses, de um trabalho que havia começado em 1987 e dado como encerrado em outubro de 1988, com a promulgação da nova Constituição Federal. Este pode ser considerado o marco nas lutas pela igualdade entre homens e mulheres no Brasil, sendo que as suas mobilizações foram bastante relevantes e marcaram o avanço das discussões feministas e dos direitos das mulheres brasileiras. Essa participação trouxe impacto tanto nos períodos que antecederam a Constituinte como efetivamente durante os seus trabalhos - que foi facilitada pela criação de órgãos públicos específicos concernentes às questões das mulheres (TELES, 2017).

Desse modo, é possível compreender que esse foi um momento paradigmático do tipo de participação, que até então era possível, dos movimentos feministas brasileiros e das mulheres na política do país. A formação da chamada "bancada feminina" no Congresso Constituinte pode exemplificar isso, tendo, na legislatura de 1987-1991, eleito 26 deputadas mulheres e nenhuma senadora - a primeira vez que se pode falar em uma bancada feminina na política brasileira. Esse era apenas um dos desafios que o movimento feminista precisaria enfrentar, a baixa representatividade política das mulheres. No entanto, embora possa parecer inexpressivo, 26 mulheres deputadas já era um número maior do que o usual para a época (PINTO, 1994).

As discussões do novo texto constitucional na Assembleia Constituinte tiveram início em 24 Subcomissões Temáticas, agrupadas em 8 Comissões Temáticas. As subcomissões representaram um importante espaço de manifestação da sociedade civil, sendo o momento de ouvir as propostas populares para que os constituintes elaborassem as suas próprias propostas, além de debaterem e demonstrarem suas próprias convicções acerca dos temas tratados (CARDOSO, 2017). Nessa época, as feministas, através do CNDM, tentaram articulações com as mulheres constituintes para poderem apresentar as suas reivindicações e demandar que estas estivessem previstas no texto constitucional. 
Sendo assim, as articulações do CNDM com as deputadas mulheres durante esse período foram muito importantes, podendo ser considerada uma novidade no cenário político brasileiro. Além disso, essa foi a primeira vez, na história do país, em que houve a criação de um grupo suprapartidário de deputadas constituintes que se articularam e ofereceram apoio à causa das mulheres. Esse era o momento que o movimento feminista tinha para imprimir a sua marca no novo texto constitucional que viria a ser promulgado e elas, de forma inteligente, tiveram percepção disso e não deixaram o momento passar sem suas participações.

Nesse sentido, é importante destacar que boa parte das manifestações do movimento feminista são visíveis na atual Constituição Federal de 1988, como a garantia da isonomia jurídica entre homens e mulheres especificamente no âmbito familiar; a proibição da discriminação de gênero no mercado de trabalho; coibição da violência contra as mulheres; a proteção da maternidade como um direito social; que resguarda o direito das presidiárias de amamentarem seus filhos; o reconhecimento do planejamento familiar como uma livre decisão do casal; entre outras importantes conquistas (TERRA, 2021).

No entanto, convém registar ainda que apesar dos esforços do movimento feminista, representado sobretudo pelo Conselho Nacional dos Direitos da Mulher e pelas deputadas integrantes da bancada feminina, nem todas as suas demandas foram atendidas. Durante o processo constituinte houveram divergências entre as demandas apresentadas pelas feministas e o que os constituintes consideravam pertinente de ser previsto pelo novo texto constitucional, principalmente no que tange aos direitos sexuais e reprodutivos, sendo que o aborto foi uma temática bastante polêmica dentro dos debates da Assembleia Constituinte (TERRA, 2021).

Apesar disso, pode-se concluir que as mulheres brasileiras e os movimentos feministas lograram êxito em sua atuação durante a Assembleia Nacional Constituinte, sendo que $80 \%$ de suas demandas foram atendidas naquele período e isso pode (e deve) ser considerado um grande avanço, ainda mais para aquela época. Além disso, foi devido aos trabalhos desempenhados pelo CNDM que pôde 
haver uma revolução dos direitos das mulheres brasileiras, pois foi a partir da sua atuação que esses passaram a ser previstos constitucionalmente (TERRA, 2021).

Ainda sobre o CNDM e sua atuação para a participação política das mulheres brasileiras, embora seja possível compreender que Conselho Nacional dos Direitos da Mulher tenha tido uma duração curta enquanto órgão de articulação das demandas das feministas e dos movimentos de mulheres em geral - sendo que o seu período de maior destaque foi o da constituinte, pois a sua efetiva atuação se deu entre o período de 1985 a 1989 - ele teve uma atuação exitosa para as brasileiras e não pode ser esquecido e nem ignorado.

Com o governo Collor, o CNDM perdeu seu orçamento e passaram a ser indicadas para a direção e como conselheiras, na maioria das vezes, mulheres com pouca tradição no movimento feminista. Diferentemente do que havia acontecido em seus primeiros anos, mesmo com a chegada do PSDB (Partido da Social-Democracia Brasileira) - partido que abriga uma das mais históricas feministas brasileiras - ao governo, em 1994, o conselho não conseguiu recuperar o espaço que havia conquistado na década de 1980. Entre 1985 e 1989, o CNDM tratou de quase todos os temas que centralizavam a luta feminista brasileira, desde questões consensuais como a luta por creches até as polêmicas ligadas a sexualidade e direito reprodutivo. Entretanto, sua maior e mais bem-sucedida intervenção aconteceu junto à Assembleia Nacional Constituinte, êxito concretizado na própria Constituição de 1988 (PINTO, 2003, p. 72).

Assim, pode-se compreender que o período de grande destaque do Conselho Nacional dos Direitos da Mulher se deu durante a segunda metade da década de 1980, durante os trabalhos desempenhados para a constituinte, sendo que posteriormente ele perderia sua força política. Apesar disso, a sua importância e relevância para as mulheres e as feministas brasileiras não é de forma alguma diminuída, sendo que esse imprimiu marcas que podem ser até hoje visualizadas na representação e participação política feminina no Brasil, pois trouxe importantes conquistas para elas, tendo marcado a Constituição de 1988 e possibilitado que houvesse aberturas institucionais para as mulheres brasileiras.

\section{CONSIDERAÇÕES FINAIS}


Fruto das articulações e mobilizações do movimento feminista, o Conselho Nacional dos Direitos da Mulher revolucionou os direitos das mulheres brasileiras e suas participações na política e nas tomas de decisões. Enquanto órgão governamental, esse representou um importante mecanismo de atuação entre o Estado, as mulheres e os movimentos feministas durante todo o processo constituinte. Desse modo, pode-se concluir que a segunda metade da década de 1980 testemunhou o sucesso do CNDM, principalmente no que tange as suas demandas para a Constituição Federal de 1988.

Sendo assim, o marco temporal definido para esse trabalho coincide com um momento de importantes e aceleradas mudanças no contexto histórico e político do Brasil. A pesquisa demostrou que as articulações do movimento feminista para a criação do CNDM e, a partir dele, a edição da Carta das Mulheres Brasileiras aos Constituintes, foram fundamentais para a participação das mulheres e para as reivindicações dos seus direitos na Constituição Federal que naquele momento passava a ser elaborada.

Diante disso, considerou-se importante registar as demandas apresentadas pelo movimento feminista, representadas pelo CNDM, durante o período constituinte e como se deu a participação das mulheres brasileiras naquele momento. Para tanto, o trabalho procurou dar ênfase aos atores convencionais do jogo político e também às integrantes desse movimento, que se articularam com as deputadas constituintes para garantir que os seus direitos fossem previstos constitucionalmente.

Antes do período da redemocratização do país e da Constituição Federal de 1988 entrar em vigor, muitos dos direitos das mulheres que atualmente parecem indispensáveis não eram garantidos pela legislação. Diante desse cenário, grande parcela da população brasileira passou a questionar essa situação de subalternidade das mulheres, reunindo-se em movimentos sociais que reivindicavam por mais direitos e por direitos iguais. As feministas passaram a demonstrar a sua 
insatisfação com as desigualdades a que elas estavam sujeitas e enxergaram no processo constituinte a oportunidade que tinham para garantirem os seus direitos no texto constitucional.

As suas participações se deram, em grande parte, através do Conselho Nacional dos Direitos da Mulher. Esse órgão foi de fundamental importância para as brasileiras, sendo que encaminhou suas propostas legislativas para a constituinte e muitas delas acabaram por estar incluídas no texto constitucional. Essas propostas haviam sido apresentadas na Carta das Mulheres Brasileiras aos Constituintes, o que permite concluir que ambos o Conselho e esse documento foram fundamentais para reivindicar os direitos das mulheres e para a atuação do Estado em conjunto com as feministas.

Diante disso, pode-se compreender que a busca pela redemocratização não dizia respeito apenas às instituições políticas, mas também às relações entre homens e mulheres nas esferas sociais e jurídicas. As mulheres brasileiras e os movimentos feministas marcaram a nova Constituição, estando muitas de suas reivindicações incorporadas ao texto constitucional. Desse modo, a sua promulgação, em 1988, pode ser considerada um importante marco no avanço dos direitos das mulheres e da igualdade de gênero no país.

Por fim, cabe destacar que embora essa pesquisa tenha feito um recorte temporal da atuação do CNDM, do momento da sua criação em 1985 até a promulgação da Constituição Federal de 1988, a atuação desempenhada por ele naquele momento gera reflexos até hoje. Isso pode ser compreendido pelo fato de que as suas demandas se encontram incorporadas no texto jurídico mais importante do país, que é a Constituição Federal, e dele decorrem outros importantes direitos. Desse modo, esse trabalho conclui com a tese de que a representação política articulada por esse Conselho pode ser considerada revolucionária no que diz respeito a atuação dos movimentos feministas e na conquista dos direitos das mulheres no país, indo além do momento constituinte e sendo uma das atuações mais importantes desempenhadas por elas até hoje. 


\section{REFERÊNCIAS}

ALVES, Branca Moreira. A luta das sufragistas. In: HOLLANDA, Heloísa Buarque de (org.). Pensamento feminista brasileira: formação e contexto. Rio de Janeiro: Bazar do Tempo, 2019.

AVELAR, Lúcia. Mulheres na elite política brasileira. 2. ed. São Paulo: Fundação Konrad; Adenauer: Editora da Unesp, 2001.

BIROLI, Flávia. Gênero e desigualdades: limites da democracia no Brasil. São Paulo: Boitempo, 2018.

BRASIL. Lei $n^{\circ}$ 7.353, de 29 de agosto de 1985. Cria o Conselho Nacional dos Direitos da Mulher - CNDM e dá outras providências. Brasília, DF: Presidência da República, 29 ago. 1985. Disponível em:

http://www.planalto.gov.br/ccivil_03/leis/1980-1988/L7353.htm. Acesso em: 26 jun. 2021.

CARDOSO, Rodrigo Mendes. A participação popular na Assembleia Nacional Constituinte de 1987-1988. Rio de Janeiro: Lumen Juris, 2017.

KARAWEJCZYK, Mônica. Mulher deve votar? O código eleitoral de 1932 e a conquista do sufrágio feminino através das páginas dos jornais Correio da Manhã e À Noite. Jundiaí: Paco Editorial, 2019.

LUZ, Cícero Krupp da; SIMÕES, Bárbara Helena. "Sim, elas podem!" Os avanços e entraves na representatividade política como empoderamento feminino no Brasil e na Índia. Revista Eletrônica Direito e Sociedade, Canoas, v. 4, n. 2, p. 69-89, nov. 2016. Disponível em:

https://revistas.unilasalle.edu.br/index.php/redes/article/view/2318-8081.16.25.

Acesso em: 12 nov. 2021.

LUZ, Cícero Krupp da; TERRA, Bibiana de Paiva. "Constituinte para valer tem que ter direitos da mulher": A participação do movimento feminista no processo constituinte de 1987 e 1988. In: ALVES,Carla Rosane da Silva Tavares; SILVELLO, João Pedro de Carvalho; GOULARTE, Nariel Diotto; Roana Funke; GARCÊS, Solange Beatriz Billig (orgs.). Pesquisa e Sociedade: Linguagens e Práticas Contemporâneas. Cruz Alta: Editora Ilustração, 2021. 
PEDRO, Joana Maria. Corpo, prazer e trabalho. In: PINSKY, Carla Bassanezi; PEDRO, Joana Maria (orgs.). Nova história das mulheres no Brasil. São Paulo: Contexto, 2018.

PILATTI, Adriano. A constituinte de 1987-1988: progressistas, conservadores, ordem econômica e regras do jogo. 3. ed. Rio de Janeiro: Lumen Juris, 2019.

PIMENTA, Fabrícia Faleiros. Políticas feministas e os feminismos na política: O Conselho Nacional dos Direitos da Mulher (1985-2005). 2010. Tese (Doutorado em História) - Universidade de Brasília, Brasília, 2010. Disponível em: https://repositorio.unb.br/handle/10482/8424. Acesso em: 12 nov. 2021.

PIMENTEL, Sílvia. A mulher e a constituinte: uma contribuição ao debate. 2. ed. São Paulo: Cortez; EDUC, 1987.

PINTO, Céli Regina Jardim. Feminismo, História e Poder. Revista de Sociologia e Política, Curitiba, v. 18, n. 36, p. 15-23, jun. 2010. Disponível em:

https://doi.org/10.1590/S0104-44782010000200003. Acesso em: 12 nov. 2021.

PINTO, Céli Regina Jardim. Participação (Representação?) Política da Mulher no Brasil: Limites e Perspectivas. In: SAFFIOTI, Heleieth; MUÑOZ-VARGAS, Mônica (orgs.). Mulher brasileira é assim. Rio de Janeiro: Rosa dos Tempos: NIPAS; Brasília: Unicef, 1994.

PINTO, Céli Regina Jardim. Uma história do feminismo no Brasil. São Paulo: Editora Fundação Perseu Abramo, 2003.

PITANGUY, Jacqueline. A carta das mulheres brasileiras aos constituintes: memórias para o futuro. In: HOLLANDA, Heloisa Buarque de (org.). Pensamento feminista brasileiro: formação e contexto. Rio de Janeiro: Bazar do Tempo, 2019.

PITANGUY, Jacqueline. As mulheres e a Constituição de 1988. [S.I.]: [s.n.], [2017]. Disponível em http://cepia.org.br/wp-content/uploads/2017/11/nov089.pdf. Acesso em 30 jun. 2021.

PITANGUY, Jacqueline. Celebrando os 30 Anos da Carta das Mulheres Brasileiras aos Constituintes. In: SEMINÁRIO 30 ANOS DA CARTA DAS MULHERES AOS CONSTITUINTES, 2018, Rio de Janeiro. Anais de Seminários 30 anos da Carta 
das Mulheres aos Constituintes. p. 43-55. Rio de Janeiro: EMERJ, 2018.

Disponível em:

https://www.emerj.tjrj.jus.br/publicacoes/serie_anais_de_seminarios/2018/versaodigit al/42/. Acesso em: 12 nov. 2021.

RODRIGUES, Marly. O Brasil da Abertura: De 1974 à Constituinte. São Paulo: Atual, 1990.

TELES, Maria Amélia de Almeida. Breve história do feminismo no Brasil e outros ensaios. São Paulo: Editora Alameda, 2017.

TERRA, Bibiana de Paiva Francisco Beraldo Borges de Sant'Ana. A Carta das Mulheres Brasileiras aos Constituintes: O Movimento Feminista e a Participação das Mulheres no Processo Constituinte de 1987-1988. 2021. Dissertação (Mestrado) - Faculdade de Direito Do Sul de Minas, Pouso Alegre, 2021. 